\title{
Microstructure and Mechanical Strength of Attritor-Milled and Spark Plasma Sintered Mg-4Y-3Nd Alloy
}

 \\ and Robert Král ${ }^{1} \mathbb{D}$ \\ 1 Department of Physics of Materials, Charles University, Ke Karlovu 5, 12116 Prague, Czech Republic; \\ 1zemkova.maria1@gmail.com (M.Z.); knapek@karlov.mff.cuni.cz (M.K.); sasekstanislav@seznam.cz (S.Š.); \\ dittrich.jan.cz@gmail.com (J.D.); rkral@met.mff.cuni.cz (R.K.) \\ 2 Nuclear Physics Institute of CAS, Řež 130, 25068 Řež, Czech Republic \\ * Correspondence: peter.minarik@mff.cuni.cz; Tel.: +420-95155-1360
}

Received: 8 June 2020; Accepted: 30 June 2020; Published: 3 July 2020

\begin{abstract}
Gas-atomized powder of an Mg-4Y-3Nd magnesium alloy was attritor-milled at room temperature in an argon atmosphere for two time periods- -1.5 and $5 \mathrm{~h}$. Subsequently, the gas-atomized powder as well as both of the milled powders were spark plasma sintered at four temperatures, 400 , 450,500 , and $550{ }^{\circ} \mathrm{C}$, for $3 \mathrm{~min}$. The effect of the milling on the powder particles' morphology and the microstructure of the consolidated samples were studied by advanced microscopy techniques. The effect of the microstructural changes, resulting from the pre-milling and the sintering temperature, on the mechanical strength was investigated in compression along and perpendicular to the sintering load direction. Both the compression yield strength and ultimate compression strength were significantly affected by the grain size refinement, residual strain, secondary phase particles, and porosity. The results showed that attritor-milling imposed severe deformation to the powder particles, causing a significant grain size refinement in all of the consolidated samples. However, $1.5 \mathrm{~h}$ of milling was insufficient to achieve uniform refinement, and these samples also exhibited a distinctive anisotropy in the mechanical properties. Only a negligible anisotropy and superior yield strength were observed in the samples sintered from $5 \mathrm{~h}$ milled powder, whereas the ultimate strength was lower than that of the samples sintered from the gas-atomized powder.
\end{abstract}

Keywords: magnesium; spark plasma sintering; attritor-milling; microstructure; mechanical strength

\section{Introduction}

The classical preparation methods of metallic materials, such as casting, followed by extrusion and/or severe plastic deformation techniques, are capable of producing large volumes of the material, but the process is time-consuming and requires specific machinery. Furthermore, the subsequent machining to prepare the final shapes results in significant material loss. In addition, deformation-based processing techniques often cause the formation of a crystallographic texture, resulting in anisotropy in the material properties [1]. On the other hand, a near net-shape production through the utilization of powder metallurgy often outperforms this "classical" approach [2]. The modern powder metallurgy techniques may, therefore, provide significant reduction in the material preparation cost through a combination of fast throughput and limited waste. This holds, in particular, when (ultra) fine-grained materials need to be prepared.

The spark plasma sintering (SPS) technique belongs to the modern powder metallurgy techniques, especially because of its unparalleled heating and cooling rates, which enable fast processing. 
The temperature is increased by the generation of Joule heat, resulting from an electric current passing through the powder. A good control of the temperature and uniaxial load applied during the processing usually results in a dense material with a lower residual porosity in comparison with the other powder consolidation techniques [3]. Thanks to the high heating and cooling rates, the final microstructure often retains the microstructure of the sintered powder. This is another key benefit of the SPS method, which, in turn, opens many possibilities for tailoring the final microstructure and related physical properties of the resulting material.

Pre-processing of the metal powders often comprises mechanical milling by various techniques and in various environments, including milling in an inert atmosphere (dry-milling) [4,5], in liquid media (wet-milling) [6], or milling in liquid nitrogen/argon (cryo-milling) [3,4,7,8]. The resulting microstructure of the powder significantly depends on all of the milling conditions and the milling time. In the case of magnesium alloys, milling is usually employed to fragment powder particles, refine the inner structure, and disrupt the oxide layer, which typically occurs on the powder particles surface and retards diffusion during sintering $[4,6]$.

The present study focuses on one of the most commercially successful magnesium alloy systems-Mg-rare earth elements (RE). This system is mostly represented by the WE (Mg-Y-RE) alloys prepared by alloying $\mathrm{Mg}$ with yttrium and RE mischmetal (unspecified combination of rare earth metals, e.g., neodymium, cerium, and lanthanum). WE alloys exhibit an excellent high-temperature stability and creep resistance [7], corrosion resistance [9], and higher room temperature strength in comparison with other commercial magnesium alloys [8]. Therefore, these alloys are generally used for high temperature applications in the aerospace and automotive industries. Moreover, these alloys are often investigated because of their potential applications in medicine, e.g., as a resorbable biomaterial $[10,11]$. Interest in the utilization of powder metallurgy for these alloys has been continuously growing with respect to new applications and advances in the powder metallurgy techniques [11-13]. The Mg-4Y-3Nd (WN43) alloy used in this study belongs to the Mg-RE alloy system, but instead of using RE mischmetal (E), pure neodymium $(\mathrm{N})$ was selected for better control of the composition and secondary phases. In particular, the effect of the attritor-milling of gas-atomized powder on the microstructure and mechanical strength of the resulting spark plasma sintered samples was investigated in this work.

\section{Materials and Methods}

Powder of the magnesium alloy Mg-4Y-3Nd (WN43), was gas-atomized at the Clausthal University of Technology, Germany. The exact composition was analyzed by Spectro spark emission spectroscope (Berwyn, Pennsylvania, USA) to be Mg-3.6wt.\% Y-3.4wt.\% Nd. Subsequently, the powder was mechanically milled in the Union Process 01-HD attritor device (London, UK). Stainless steel balls of $6.35 \mathrm{~mm}$ in diameter, with a ball-to-powder ratio of 40:1, rotation of $300 \mathrm{rpm}$, and argon atmosphere (dry-milling) were selected for the milling. In addition, stearic acid was used as the process control agent. The milling was performed for two times- 1.5 and $5 \mathrm{~h}$. After the milling, the powder was handled in the high-purity argon atmosphere all the time in order to prevent oxidation.

The subsequent sintering was performed in a vacuum using the spark plasma sintering method in a device manufactured by FCT Systeme GmbH (Rauenstein, Germany). For all of the experiments, $5 \mathrm{~g}$ of powder was housed in a graphite die with an inner diameter of $20 \mathrm{~mm}$. Four sintering temperatures were selected based on the previous results, $400,450,500$, and $550{ }^{\circ} \mathrm{C}$, for $3 \mathrm{~min}$ (see the work of [14]). During heating, the mechanical load was increased to a value of $100 \mathrm{MPa}$, and held for the sintering period. After sintering, the load was released and the final compact was rapidly cooled down.

The microstructure of the initial powder and milled powders, as well as of the compacted samples was studied by scanning and transmission electron microscope (SEM and TEM). The SEM FEI Quanta 200F (Hillsboro, Oregon, USA), equipped with an EDAX electron backscatter diffraction (EBSD) camera (Berwyn, Pennsylvania, USA), and the TEM JEOL FX200 (Tokyo, Japan) were used. The microstructure 
investigation of the compacted samples was carried out in two planes, parallel and perpendicular to the sintering load direction (SLD).

The mechanical strength of the sintered samples was investigated by compression deformation tests performed on an Instron 5882 (Norwood, Maryland, USA) at room temperature with an initial strain rate of $10^{-3} \mathrm{~s}^{-1}$. At least three samples with dimensions of $5 \mathrm{~mm} \times 3 \mathrm{~mm} \times 3 \mathrm{~mm}$ were cut from each material from the central part of the compacted pellet and tested, so that the loading direction (i.e., along the 5-mm edges) was parallel or perpendicular to SLD.

\section{Results}

\subsection{Microstructure}

The SEM micrograph of the initial gas-atomized powder is shown in Figure 1a. The statistical analysis of the particle size showed that its distribution was rather broad, ranging from several $\mu \mathrm{m}$ up to $170 \mu \mathrm{m}$, and the D50 value (median diameter) was $49 \mu \mathrm{m}$ [14]. The mechanical attritor-milling for 1.5 and $5 \mathrm{~h}$ resulted in a significant change in the particle shape, and the size of the individual particles was more uniform (cf. Figure $1 \mathrm{a}-\mathrm{c}$ ). The spherical gas-atomized powder particles turned into the disc-like ones. An increase in the milling time from 1.5 to $5 \mathrm{~h}$ resulted in an increase in the powder particles flatness, while the diameter of the largest particles was not affected. Moreover, after $5 \mathrm{~h}$, the majority of the particles had a diameter above $150 \mu \mathrm{m}$, as clearly shown in Figure 1c. The significant increase in the average particle size observed after the milling can be associated with continuous fragmentation and cold-welding, which is often observed in the mechanically milled powder.

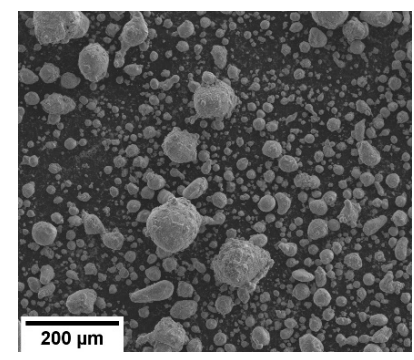

(a)

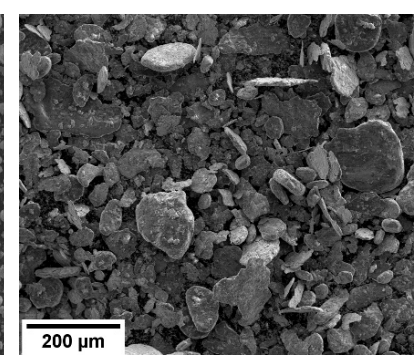

(b)

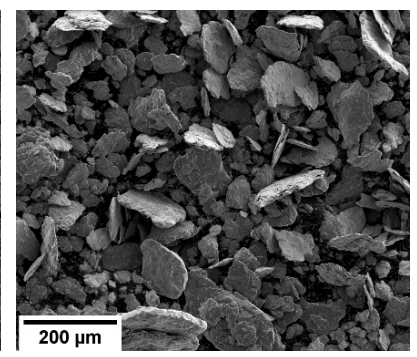

(c)

Figure 1. SEM micrographs of (a) initial powder and powder milled for (b) 1.5 and (c) $5 \mathrm{~h}$.

The powders in all three conditions, gas-atomized, $1.5 \mathrm{~h}$ milled, and $5 \mathrm{~h}$ milled, were subsequently sintered by SPS using identical conditions, $400,450,500$, and $550{ }^{\circ} \mathrm{C}$, for $3 \mathrm{~min}$. The microstructure dependence on the powder conditions and sintering temperature was investigated by SEM and TEM, with a particular emphasis on the secondary phase particles, and by EBSD, which provided good statistical information regarding the grain structure and residual strain. Figure 2 shows the SEM microstructure of the samples sintered from all three types of the WN43 powder. Note that all of the types of samples were investigated, but only the micrographs of the samples sintered at $550{ }^{\circ} \mathrm{C}$ are shown. It is clear that the microstructure of the compacts was significantly affected by the milling and milling time. The most distinct feature observed in all of the samples was the sub-structure formed by the former powder particles. In particular, in the case of the sample sintered from the gas-atomized powder, the particle boundaries became highly enriched by the alloying elements, while their surroundings became depleted. This tendency to occupy powder boundaries, which intensifies with the increasing sintering temperature, was already investigated in a previous study $[11,14]$. On the other hand, an increase in the imposed deformation with the increasing milling time caused a weakening of this effect. The former particle boundaries were decorated only partially in the sample sintered from the $1.5 \mathrm{~h}$ milled powder, and, in addition, the decoration was distinct primarily in the case of particles that were less deformed. In the case of the sample sintered from the $5 \mathrm{~h}$ milled powder, almost no decoration was observed. It should be also noted that the disc-like shape 
of the milled powder particles caused a preferential formation of the layered structure, which was more pronounced in the sample sintered from the $5 \mathrm{~h}$ milled powder. However, these discs consist of highly deformed, fragmented, and cold-welded pieces. Therefore, the microstructure is not utterly disc-based as reported (e.g., in $[6,15])$, but it is more isotropic (cf. Figure 2c,d).

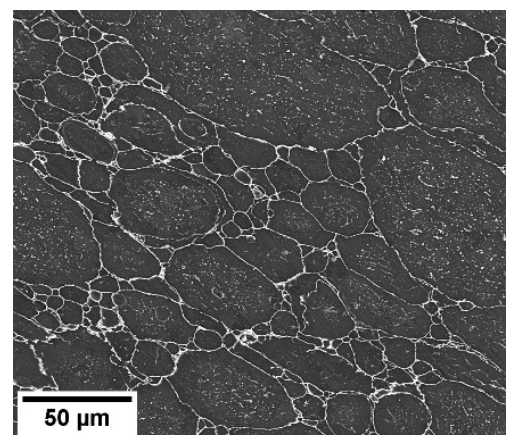

(a)

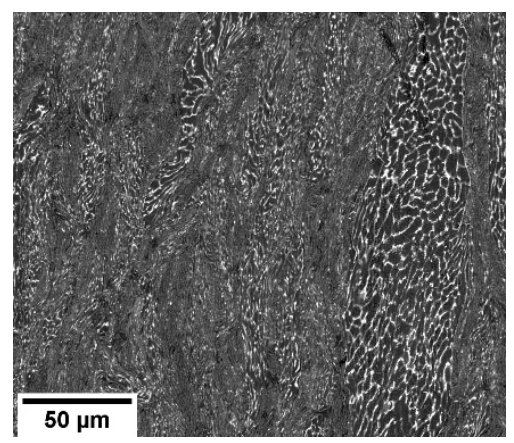

(c)

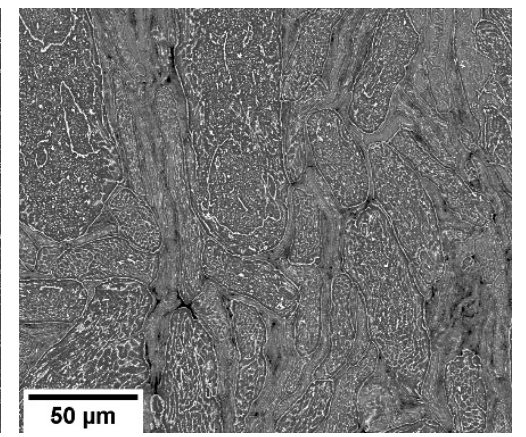

(b)

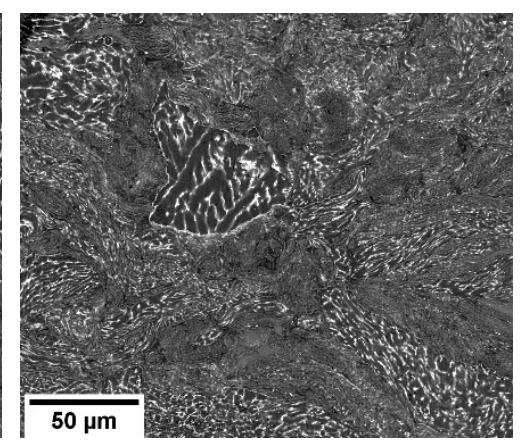

(d)

Figure 2. SEM micrographs of the samples sintered at $550^{\circ} \mathrm{C}$ for $3 \mathrm{~min}$ from (a) gas-atomized, (b) $1.5 \mathrm{~h}$ milled, and (c) $5 \mathrm{~h}$ milled powder-cross-sections parallel with sintering load direction (SLD; horizontal direction in the images). (d) SEM micrograph of the sample sintered at $550{ }^{\circ} \mathrm{C}$ for $3 \mathrm{~min}$ from $5 \mathrm{~h}$ milled powder-cross-section perpendicular to SLD.

The distribution of the secondary phases became significantly affected by the milling as well. The effect of the sintering temperature on the phase structure within the initial gas-atomized powder particles in the compacted samples was investigated in the previous study [14]. That work showed that the increase in the sintering temperature resulted in a dissolution of the former dendritic structure formed during gas-atomization, and a consequent re-precipitation of fine secondary phase particles of the entire Mg-Nd-Y precipitation series [16]. Similar behavior was also expected in the case of the milled powder. The TEM micrographs of the samples sintered at $550{ }^{\circ} \mathrm{C}$ from the gas-atomized powder (Figure 3a) and from $5 \mathrm{~h}$ milled powder (Figure $3 \mathrm{~b}, \mathrm{c}$ ) revealed that this assumption was correct. Nevertheless, despite all of the types of secondary phase particles that were observed in the sample sintered from the milled powder, the size and distribution of the precipitates and/or secondary phase particles was significantly different. In the sample sintered from the gas-atomized powder, disc-like precipitates were observed in the central part of the former powder particles, while large areas along the former powder boundaries were precipitate-free (see Figures 2a and 3a, and [14]). On the other hand, in the case of the sample sintered from $5 \mathrm{~h}$ milled powder, the distribution of precipitates was more uniform, their size was much smaller, and their shape was usually needle-like (see Figure $3 b, c$ ). In addition, severe residual strain was observed in the sample sintered from the pre-milled powder (see Figure 3b). 


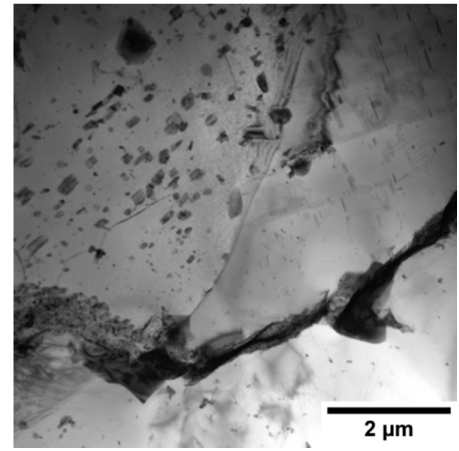

(a)

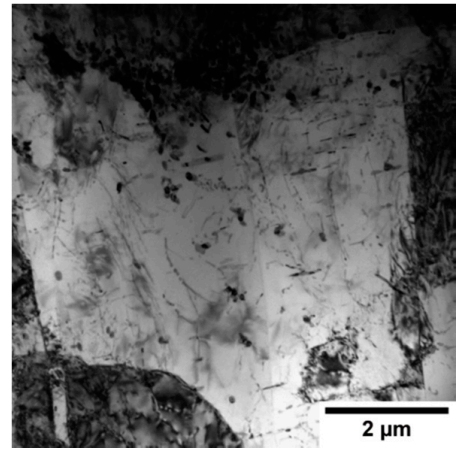

(b)



(c)

Figure 3. TEM micrographs of the samples sintered at $550{ }^{\circ} \mathrm{C}$ for $3 \mathrm{~min}$ from (a) gas-atomized, (b) $5 \mathrm{~h}$ milled powder, and (c) detail of (b).

The measurement of the residual porosity revealed that almost full density was achieved in all types of the sintered materials. The relative porosity was calculated from at least ten high-resolution SEM images with reasonable magnification. The resulting values are shown in Table 1 . The highest porosity was measured in the samples sintered at $400^{\circ} \mathrm{C}$ for $3 \mathrm{~min}$ from both of the pre-milled powders. An increase in the sintering temperature resulted in a continuous decrease in the relative porosity, regardless of the powder condition.

Table 1. Relative porosity (in \%) calculated from high-resolution SEM images.

\begin{tabular}{ccccc}
\hline \multirow{2}{*}{ Powder Condition } & \multicolumn{4}{c}{ Sintering Temperature } \\
\cline { 2 - 5 } & $\mathbf{4 0 0}{ }^{\circ} \mathbf{C}$ & $\mathbf{4 5 0}{ }^{\circ} \mathbf{C}$ & $\mathbf{5 0 0}{ }^{\circ} \mathbf{C}$ & $\mathbf{5 5 0}{ }^{\circ} \mathbf{C}$ \\
\hline gas-atomized & $0.4(1)$ & $0.3(1)$ & $<0.1$ & $<0.1$ \\
\hline 1.5 h milled & $1.1(3)$ & $0.9(1)$ & $0.5(1)$ & $0.6(1)$ \\
\hline 5 h milled & $1.0(5)$ & $0.6(4)$ & $0.3(1)$ & $0.2(1)$ \\
\hline
\end{tabular}

The investigation of the grain structure revealed that the average grain size and the grain size distribution vastly differed depending on the powder condition and on the sintering temperature. The formation of a bimodal grain size distribution was observed in the samples sintered at $400{ }^{\circ} \mathrm{C}$ from the gas-atomized powder (Figure 4a and in detail in [14]). The recrystallized small grains were predominantly formed along the former particle boundaries as a result of the deformation introduced to the powder during the sintering. An increase in the sintering temperature resulted in grain growth, and grain size distribution became uniform (Figure $4 \mathrm{~d}$ and in detail in [14]). Nevertheless, the average grain size of $\sim 20 \mu \mathrm{m}$ (calculated as a weighted average with area fraction as the weight) was comparable, regardless of the sintering temperature. As expected, the milling caused a significant refinement of the grain structure. An increase in the milling time primarily caused the homogenization of deformation introduced to the powder. As shown in Figure $4 \mathrm{~b}$, in the $1.5 \mathrm{~h}$ milled powder, there were still particles in which almost no deformation was present. On the other hand, highly deformed and fragmented powder particles were also present with a diameter below $1 \mu \mathrm{m}$. The increase in the milling time up to $5 \mathrm{~h}$ led to a further grain size refinement, which prevented the utilization of EBSD. The subsidiary TEM investigation (Figure 4c) revealed that most of the recrystallized grains were smaller than $500 \mathrm{~nm}$, and the larger grains were still severely deformed. An increase in the sintering temperature caused the grain growth as in the case of the gas-atomized powder. However, the grain growth was more pronounced in the short-milled powder than in the $5 \mathrm{~h}$ milled powder, even in the areas where the deformation was most pronounced. Accordingly, the average grain size calculated for the samples sintered at $550{ }^{\circ} \mathrm{C}$ from 1.5 and $5 \mathrm{~h}$ milled powder was $6 \mu \mathrm{m}$ and $2 \mu \mathrm{m}$, respectively. 


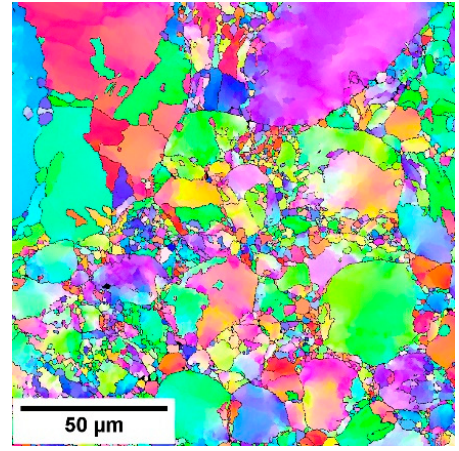

(a)

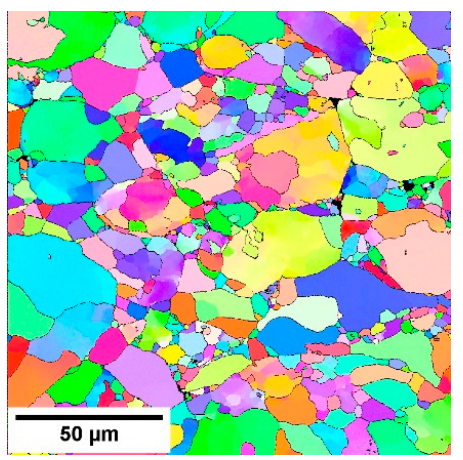

(d)

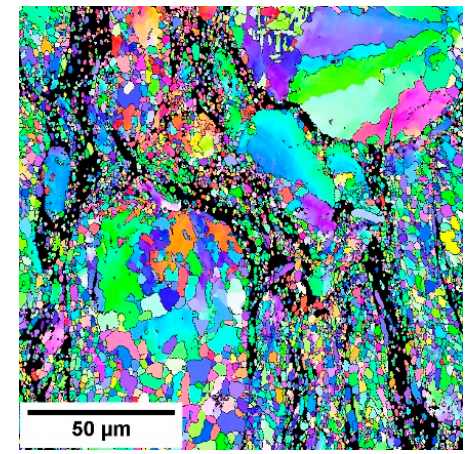

(b)

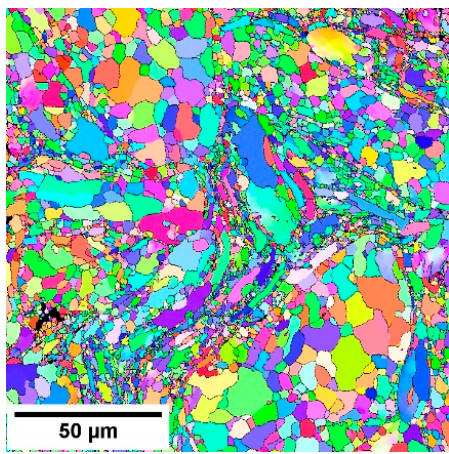

(e)

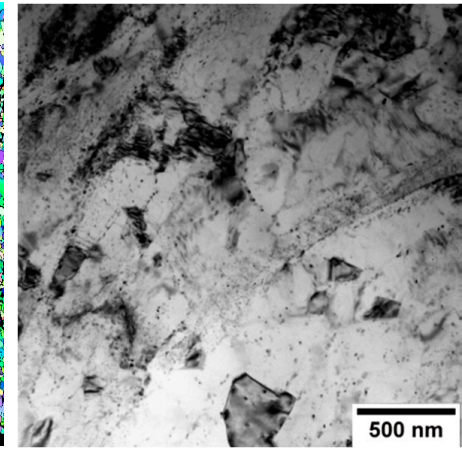

(c)

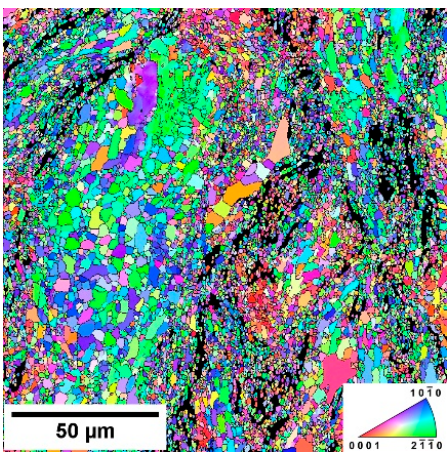

(f)

Figure 4. Electron backscatter diffraction (EBSD) orientation maps and TEM micrograph of the samples sintered from the powders in all three conditions. Gas-atomized powder sintered at (a) $400{ }^{\circ} \mathrm{C}$ and (d) $550{ }^{\circ} \mathrm{C}$ for $3 \mathrm{~min}, 1.5 \mathrm{~h}$ milled powder sintered at (b) $400{ }^{\circ} \mathrm{C}$ and (e) $550{ }^{\circ} \mathrm{C}$ for $3 \mathrm{~min}$, and $5 \mathrm{~h}$ milled powder sintered at (c) $400{ }^{\circ} \mathrm{C}$ and (f) $550^{\circ} \mathrm{C}$ for $3 \mathrm{~min}$. Cross-sections are parallel with SLD (applied in the image horizontal direction).

\subsection{Mechanical Properties}

The effect of the milling and sintering parameters on the mechanical strength was investigated in all of the samples by compression deformation tests performed in two directions-parallel to SLD and perpendicular to SLD. The evolution of the compression yield strength (CYS) and the ultimate compression strength (UCS) as a function of the sintering temperature are shown for all of the samples in Figure 5. As with the microstructure, the mechanical strength of the samples significantly depended on both the sintering temperature and on the powder condition. The CYS values measured in the samples sintered at $400{ }^{\circ} \mathrm{C}$ were comparable ( 180-200 MPa), regardless of the powder condition and the deformation direction. The only exception was the sample sintered from $1.5 \mathrm{~h}$ milled powder and loaded perpendicular to SLD, which was too brittle and broke already in the elastic region. An increase in the sintering temperature had a significantly different impact on the samples sintered from gas-atomized and $1.5 \mathrm{~h}$ milled powder, as well as the samples sintered from $5 \mathrm{~h}$ milled powder. In the case of both the gas-atomized and $1.5 \mathrm{~h}$ milled powder, a continuous deterioration of mechanical strength was observed from $\sim 190 \mathrm{MPa}\left(400{ }^{\circ} \mathrm{C}\right)$ to $\sim 160 \mathrm{MPa}\left(550{ }^{\circ} \mathrm{C}\right)$. The evolution was almost identical for both powder conditions and both deformation directions. As mentioned above, the only exceptions were the samples sintered from $1.5 \mathrm{~h}$ milled powder and loaded perpendicular to SLD, which were too brittle in the case of the 400 and $450{ }^{\circ} \mathrm{C}$ sintering temperature, and still rather weak at $500^{\circ} \mathrm{C}$. On the other hand, an increase in the sintering temperature resulted in an increase in CYS for the samples sintered from the $5 \mathrm{~h}$ milled powder. The CYS values of the samples loaded parallel with SLD increased from $\sim 190 \mathrm{MPa}\left(400{ }^{\circ} \mathrm{C}\right)$ to $\sim 220 \mathrm{MPa}\left(450^{\circ} \mathrm{C}\right)$ and then saturated, while CYS of the samples loaded perpendicular to SLD reached saturation at $500{ }^{\circ} \mathrm{C}$, with a value of $\sim 245 \mathrm{MPa}$. 


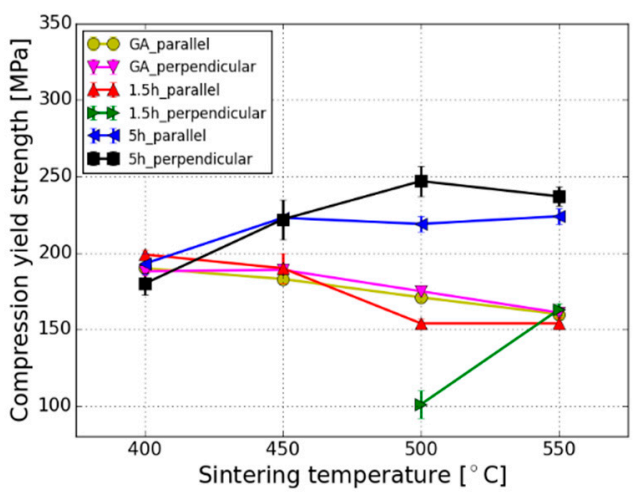

(a)

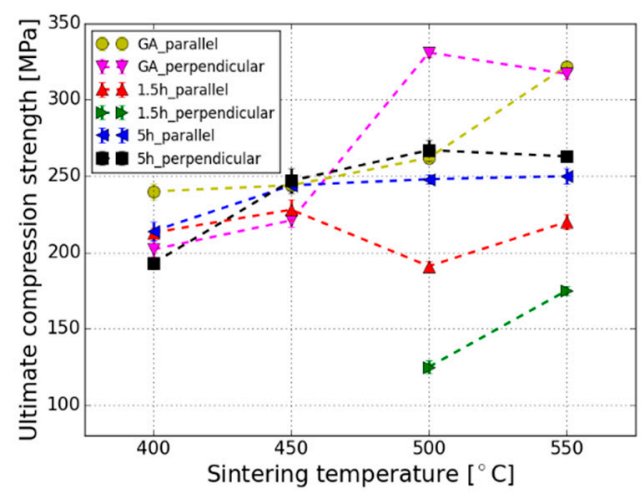

(b)

Figure 5. (a) compression yield strength ad (b) ultimate compression strength calculated from the compression curves of the samples sintered from gas-atomized (GA), $1.5 \mathrm{~h}$ milled (1.5 h), and $5 \mathrm{~h}$ milled $(5 \mathrm{~h})$ powder in two directions-parallel to SLD and perpendicular to SLD.

The evolution of UCS was significantly different than that of CYS, especially in the case of the samples sintered from the gas-atomized powder. Despite the pronounced deterioration of CYS with the increasing sintering temperature, UCS significantly increased and reached $\sim 320 \mathrm{MPa}$ for the samples sintered at $550{ }^{\circ} \mathrm{C}$, regardless of the loading direction. On the other hand, the dependence of UCS on the sintering temperature was affected by the deformation direction in the samples sintered at 400, 450, and $500{ }^{\circ} \mathrm{C}$ rather ambiguously, as shown in Figure 5b. Interestingly, the UCS values of the samples sintered from the $5 \mathrm{~h}$ milled powder were only slightly higher than the CYS values, showing only a small hardening ability. For all of the temperatures and deformation directions, a hardening of only $\sim 20 \mathrm{MPa}$ was observed in these samples. In the case of the samples sintered from $1.5 \mathrm{~h}$ milled powder, UCS did not exhibit any clear trend for parallel loading, and the values ranging from 190 to $230 \mathrm{MPa}$ were observed, whereas, as mention above, the strength of the samples loaded perpendicular to SLD was inferior.

\section{Discussion}

Mechanical milling of the gas-atomized powder always results in the introduction of high amount of strain into the powder particles. Nevertheless, milling conditions, such as the milling method, temperature, and medium, significantly affect the efficiency of milling and deformation modes. It has been shown in previous studies that attritor-milling is more effective than other common milling methods, such as ball-milling [17]. Regarding the medium, dry-milling results in more intensive fragmentation and cold-welding than milling in the liquid media (cf. [5] and [6]). Consequently, the evolution of the powder morphology observed in this study with increasing the time of the attritor-milling is in consistence with the previous results. As mentioned in the introduction, one of the most important benefits of SPS is its ability to retain, at least to some extent, the microstructure of the sintered powder. Sintering at $400{ }^{\circ} \mathrm{C}$ showed that there is a substantial difference in the microstructure of the individual samples with respect to the powder condition. The samples sintered from the gas-atomized powder exhibited a bimodal grain size distribution, with small grains preferably distributed along the former powder boundaries. The formation of such a distribution has been revealed and discussed in our previous studies (see, e.g., [14,18]). It has been shown that small grains form preferentially in highly deformed areas, where deformation concentrated during the sintering due to the application of external load. On the other hand, the attritor-milling imposed deformation to the powder particles before sintering, and the load applied during the compactization had only an inferior additional effect. Therefore, the recrystallization did occur more uniformly in the compacted samples, and mainly depended on the uniformity of the strain introduced by the milling. 
This is particularly visible by comparing the samples sintered from the $1.5 \mathrm{~h}$ and $5 \mathrm{~h}$ milled powder (see Figure 4). The attritor milling for $1.5 \mathrm{~h}$ was insufficient to impose comparable deformation to all powder particles, and, consequently, the presence of non-deformed powder particles resulted in the occurrence of relatively large grains in the consolidated samples (Figure 4b). On the other hand, a more uniform (ultra) fine-grained microstructure was observed in the sample made from the powder milled for $5 \mathrm{~h}$.

The mechanical properties of a material are characteristically strongly connected with its microstructure. It is, therefore, rather surprising that the CYS of all of the investigated samples sintered at $400{ }^{\circ} \mathrm{C}$ was comparable (Figure 5a). Note that the deformation was performed along two mutually perpendicular axes, and, therefore, texture weakening, which is often observed after severe plastic deformation, cannot be considered for this case [19]. The grain structure in the sample sintered from the gas-atomized powder was much coarser than that of both milled samples. In addition, pre-milling caused an increase in the residual strain, which is clearly visible in Figure 4c. According to the Hall-Petch relation, large grains are able to contain more dislocations piled up at the grain boundary [20]. Their stress field facilitates a dislocation movement through the grain boundary. A decrease in the grains size has a negative impact on the number of dislocations, which can form inside the grain, and, therefore, an increase in the external load is needed to compensate for this effect [20]. On the other hand, it has been shown that a high density of dislocations may have a negative impact on the materials strength in the ultrafine-grained materials. The high dislocation density already present within the grains, as a result of mechanical milling, may readily facilitate dislocation transfer through the grain boundary, regardless of the small grain size [21]. Consequently, the amount of residual strain that increased with the milling time likely compensated for the obvious grain size refinement and the yield strength of all of the samples was comparable.

The increase in the sintering temperature caused the deterioration of CYS in the samples sintered from the gas-atomized powder, as well as in the samples milled for $1.5 \mathrm{~h}$. This can be explained in terms of grain growth and from a decrease in the residual strain, which caused softening in the samples sintered at $400{ }^{\circ} \mathrm{C}$. In addition, an increase in the sintering temperature caused the dissolution of the secondary phase particles, as described in the literature [14]. On the other hand, these softening effects "cleaned" the microstructure, and, therefore, promoted the activation of twinning and standard dislocation hardening, even in small grains. The effect of the increasing sintering temperature caused a significant increase in UCS, especially in the samples sintered from the gas-atomized powder, in which only a negligible porosity (Table 1) was measured at a sintering temperature of $500{ }^{\circ} \mathrm{C}$ and above.

As shown above, the microstructure of the samples sintered from $1.5 \mathrm{~h}$ milled powder was composed of non-deformed and partially deformed powder particles, as well as of deformed disc-like particles. This combination of different shapes resulted in a slightly increased porosity (Table 1), which caused the premature failure of the samples deformed perpendicularly to SLD. In other words, the samples strained in perpendicular direction to SLD (i.e., in parallel with the disc-particles plane) were brittle because the crack growth during compression was much easier in comparison to the samples deformed in parallel to SLD (i.e., perpendicularly to the disc-particles plane). Therefore, plastic deformation occurred only in the samples sintered at a temperature of $500{ }^{\circ} \mathrm{C}$ and above, in which the residual porosity decreased and the sintering efficiency increased. The evolution of UCS in the samples sintered from the $1.5 \mathrm{~h}$ milled powder did not exhibit any trend when the deformation was performed parallel with SLD, and the UCS values only slightly exceeded the CYS values when the deformation was performed perpendicular to SLD. Therefore, it can be concluded that the UCS values were significantly affected by all of the softening effects discussed above, as well as by the residual porosity and particle shape.

A different evolution of the CYS values was observed in the case of the samples sintered from $5 \mathrm{~h}$ milled powder. The increase in the sintering temperature also caused a decrease in the internal strain, but a much more uniform and finer microstructure was formed in comparison with the samples sintered from the $1.5 \mathrm{~h}$ milled powder. Therefore, an increase in the CYS values was observed as a function of 
the sintering temperature. The relatively low strengthening ability observed in the samples sintered from the $5 \mathrm{~h}$ milled powder may be attributed to the residual strain that decreased with the increasing sintering temperature, but was still relatively high even in the sample sintered at $550{ }^{\circ} \mathrm{C}$, as shown in Figure $3 \mathrm{~b}$. A higher extent of fragmentation and cold welding caused the formation of a more isotropic microstructure in terms of the powder particles shape (Figure 2). Therefore, despite the comparable porosity with the samples sintered from $1.5 \mathrm{~h}$ milled powder, especially at lower sintering temperatures, brittle behavior was not observed. Furthermore, the samples sintered from the $5 \mathrm{~h}$ milled powder exhibited a rather isotropic deformation behavior with respect to the studied mechanical properties, as can be concluded from the comparison of both, mutually perpendicular, deformation directions.

\section{Conclusions}

The gas-atomized and attritor-milled powders of WN43 magnesium alloy were consolidated by the SPS technique (at 400,450,500, and $550^{\circ} \mathrm{C}$ for $3 \mathrm{~min}$ ). Milling was performed for $1.5 \mathrm{~h}$ and $5 \mathrm{~h}$ in an argon atmosphere. Subsequently, the effect of milling time and sintering temperature on the microstructure and mechanical properties was investigated. The following conclusions may be drawn from this study:

- The milling had a significant effect on the powder particles size and morphology. A change in both these parameters resulted from severe fragmentation and cold-welding, the extent of which increased with the increasing milling time.

- Severe plastic deformation imposed to the powder resulted in a significant grain size refinement in the sintered samples when compared to the ones sintered from gas-atomized powder. Nevertheless, relatively large grains were observed in the samples consolidated from $1.5 \mathrm{~h}$ milled powder, whereas almost uniform (ultra)fine-grained microstructure was observed in the samples sintered from the $5 \mathrm{~h}$ milled powder.

- Microstructural changes imposed by the milling had a strong effect on the mechanical properties of the consolidated samples. Both CYS and UCS were significantly affected, especially by the grain size refinement, residual strain, secondary phase particles, and porosity.

- Mechanical properties of the samples sintered from $1.5 \mathrm{~h}$ milled powder exhibited pronounced anisotropy. On the other hand, compacts of the $5 \mathrm{~h}$ milled powder showed comparable CYS and UCS when deformed along two mutually perpendicular directions.

- The attritor-milling for $5 \mathrm{~h}$ was found to be very effective for increasing CYS, especially for sintering temperatures exceeding $450^{\circ} \mathrm{C}$, whereas UCS did not exceed the values measured in the samples sintered from the gas-atomized powder.

Author Contributions: Conceptualization, P.M., M.K., and M.Z.; methodology, P.M., M.K., and M.Z.; investigation, M.Z., S.Š., and J.D.; resources, R.K.; writing (original draft preparation), M.Z., M.K., and P.M. All authors have read and agreed to the published version of the manuscript.

Funding: This work was financially supported by the Czech Science Foundation under project GA18-19213Y. Partial financial support received from ERDF under project no. CZ.02.1.01/0.0/0.0/15 003/0000485 is also acknowledged. M.Z. and J.D. gratefully acknowledge additional financial support by the Charles University Grant Agency under grants 410119 and 1172120, respectively. M.K. acknowledges partial financial support from OP RDE, MEYS, grant no. CZ.02.1.01/0.0/0.0/16 013/0001794.

Acknowledgments: No further support is acknowledged.

Conflicts of Interest: The authors declare no conflict of interest.

\section{References}

1. Janeček, M.; Yi, S.; Král, R.; Vrátná, J.; Kainer, K.U. Texture and microstructure evolution in ultrafine-grained AZ31 processed by EX-ECAP. J. Mater. Sci. 2010, 45, 4665-4671. [CrossRef]

2. Manière, C.; Torresani, E.; Olevsky, E.A. Simultaneous Spark Plasma Sintering of Multiple Complex Shapes. Materials 2019, 12, 557. [CrossRef] [PubMed] 
3. Alias, J.; Harun, W.S.W.; Ayu, H.M. A Review on the Preparation of Magnesium-Based Alloys Prepared by Powder Metallurgy and the Evolution of Microstructure and Mechanical Properties. Key Eng. Mater. 2019, 796, 3-10. [CrossRef]

4. Kim, K.R.; Ahn, J.W.; Kim, G.-H.; Han, J.H.; Cho, K.K.; Roh, J.-S.; Kim, W.J.; Kim, H.S. Corrosion behavior of magnesium powder fabricated by high-energy ball milling and spark plasma sintering. Met. Mater. Int. 2014, 20, 1095-1101. [CrossRef]

5. Hwang, S.; Nishimura, C.; McCormick, P.G. Mechanical milling of magnesium powder. Mater. Sci. Eng. A 2001, 318, 22-33. [CrossRef]

6. Minárik, P.; Zemková, M.; Kozlík, J.; Lukáč, F.; Král, R. Effect of flake-like powder morphology on the microstructure and texture in Mg-Al-RE alloy. Mater. Lett. 2020, 262, 127031. [CrossRef]

7. Mordike, B.L. Creep-resistant magnesium alloys. Mater. Sci. Eng. A. 2002, 324, 103-112. [CrossRef]

8. Kubásek, J.; Dvorský, D.; Čavojský, M.; Roudnická, M.; Vojtěch, D. WE43 magnesium alloy-material for challenging applications. Kov. Mater. 2019, 57, 159-165. [CrossRef]

9. Knapek, M.; Minárik, P.; Čapek, J.; Král, R.; Kubásek, J.; Chmelík, F. Corrosion of pure magnesium and a WE43 magnesium alloy studied by advanced acoustic emission analysis. Corros. Sci. 2018, 145, 10-15. [CrossRef]

10. Krause, A.; von der Höh, N.; Bormann, D.; Krause, C.; Bach, F.-W.; Windhagen, H.; Meyer-Lindenberg, A. Degradation behaviour and mechanical properties of magnesium implants in rabbit tibiae. J. Mater. Sci. 2010, 45, 624-632. [CrossRef]

11. Soderlind, J.; Cihova, M.; Schäublin, R.; Risbud, S.; Löffler, J.F. Towards refining microstructures of biodegradable magnesium alloy WE43 by spark plasma sintering. Acta Biomater. 2019, 98, 67-80. [CrossRef] [PubMed]

12. Dvorsky, D.; Kubasek, J.; Vojtěch, D.; Prusa, F.; Nova, K. Preparation of WE43 using powder metallurgy route. Manuf. Technol. 2016, 16, 680-687. [CrossRef]

13. Dvorsky, D.; Kubasek, J.; Jablonska, E.; Kaufmanova, J.; Vojtech, D. Mechanical, corrosion and biological properties of advanced biodegradable $\mathrm{Mg}-\mathrm{MgF}_{2}$ and $\mathrm{WE} 43-\mathrm{MgF}_{2}$ composite materials prepared by spark plasma sintering. J. Alloys Compd. 2020, 825, 154016. [CrossRef]

14. Minárik, P.; Zemková, M.; Lukáč, F.; Bohlen, J.; Knapek, M.; Král, R. Microstructure of the novel biomedical Mg-4Y-3Nd alloy prepared by spark plasma sintering. J. Alloys Compd. 2020, 819, 153008. [CrossRef]

15. Wang, X.; Jiang, L.; Zhang, D.; Beyerlein, I.J.; Mahajan, S.; Rupert, T.J.; Lavernia, E.J.; Schoenung, J.M. Reversed compressive yield anisotropy in magnesium with microlaminated structure. Acta Mater. 2018, 146, 12-24. [CrossRef]

16. Nie, J.-F. Precipitation and Hardening in Magnesium Alloys. Metall. Mater. Trans. A. 2012, 43, 3891-3939. [CrossRef]

17. Just, A.; Yang, M. Attrition Dry Milling in Continuous and Batch Modes. In Proceedings of the The Powder and Bulk Solids Conference/Exhibition, Chicago, IL, USA, 6-8 October 1997; p. 4.

18. Minárik, P.; Stráský, J.; Veselý, J.; Lukáč, F.; Hadzima, B.; Král, R. AE42 magnesium alloy prepared by spark plasma sintering. J. Alloys Compd. 2018, 742, 172-179. [CrossRef]

19. Minárik, P.; Král, R.; Čížek, J.; Chmelík, F. Effect of different c/a ratio on the microstructure and mechanical properties in magnesium alloys processed by ECAP. Acta Mater. 2016, 107, 83-95. [CrossRef]

20. Hall, E.O. The Deformation and Ageing of Mild Steel: III Discussion of Results. Proc. Phys. Soc. Sect. B 1951, 64, 747-753. [CrossRef]

21. Huang, X.; Hansen, N.; Tsuji, N. Hardening by Annealing and Softening by Deformation in Nanostructured Metals. Science 2006, 312, 249-251. [CrossRef] [PubMed]

(C) 2020 by the authors. Licensee MDPI, Basel, Switzerland. This article is an open access article distributed under the terms and conditions of the Creative Commons Attribution (CC BY) license (http://creativecommons.org/licenses/by/4.0/). 